\title{
A TENTATIVE CLASSIFICATION OF THE FORMS OF ANIMAL BEHAVIOR
}

\section{S. J. HOLMES}

University of California, Berkeley, California

A classification of the many things which animals do has, I believe, an interest not only for animal psychology but for human psychology as well; and I have therefore attempted to make a grouping of the various forms of animal behavior. What is designated as behavior is not sharply demarcated from the physiological functioning of the body. But while such activities as respiratory movements, sneezing, coughing, etc., may fall under both categories, most behavior is clearly distinguished from physiological functioning as such, although the latter is, of course, involved in behavior as in all the other activities of the organism.

An attempt to group activities, whether internal or external, brings us into contact with problems that differ from those which confront the taxonomic botanist or zoologist. The taxonomist aims to group plants and animals according to a natural system of classification, a system which purports to express the genetic relationships of the organisms with which he deals. The similarities upon which the taxonomist's grouping are founded are, if his classification is a "true" one, based upon community of descent. But the classification of the activities of animals cannot be carried out by simply taking over the methods of the taxonomist. On the other hand, such a classification cannot afford to ignore phylogeny. There is a phylogeny of activity as there is of species and of organs. Just as an organ may become differentiated in the course of evolution into a number of derivative structures, so an activity, such as the functioning of this organ, may become split up into several different modes of action. 
There are often features of behavior which are remarkably conservative such as the sucking instinct in the mammalia, but for the most part the comparative psychologist is left without any landmarks analogous to the presence of a notochord or the existence of gill slits which afford so valuable an aid in the search for morphological relationships. Tracing phylogeny, however, is a notoriously precarious business, even for the morphologist with whatever aid may be furnished by paleontology. And when it comes to classifying behavior on a genetic basis, the undertaking is beset with so many additional hazards that it is scarcely practicable in the present state of our knowledge. I have accordingly abandoned the attempt to group animal activities in a strictly genetic system.

The chief difficulties in a genetic grouping of types of behavior is the fact that various activities do not follow diverging paths, each independent of others, as in the case of families and orders of living beings; the activities of any organism are closely interrelated at all stages of evolution. There is frequent change of function which may lead a part originally employed, for instance, in locomotion, to be used at another period for the function of reproduction, as is illustrated in the first abdominal appendages of male decapod crustaceans. Let us consider briefly in this connection the evolution of behavior involved in taking food. Beyond the process of simple absorption such as occurs in plants, the most primitive method of taking in food is amoeboid engulfing which is common among the Sarcodina and in the digestive cells of primitive Metazoa. Sweeping in food by cilia or flagella affords a method of intake prevalent not only in many Protozoa, but widely distributed among lower invertebrates. An advance upon this type is by engulfing food through the muscular apparatus surrounding the oral aperture, an operation often aided by the activity of tentacles (coelenterates). This type of pharyngeal intake is common among coelenterates, flat worms, nemerteans, and many annelids. In the Arthropods we have added to the oral swallowing apparatus a number of organs (mandibles, maxillae and maxillipeds) which, in the Crustacea, are clearly to be regarded as modified locomotor appendages. The derivation of 
the jaws of vertebrates is less clear. If the lower jaw is serially homologous with the hyoid and branchial arches, its original function may have been respiratory. If so, we have another illustration of the fact that food taking comes to appropriate to itself organs and activities which previously served the interests of other functions. Tracing the evolution of the functions of reproduction we find that a part of this function in the crayfish, for instance, is concerned with appendages originally locomotor. In the course of the elaboration of this function a part of the creature's activities passes at a certain point in evolution from a service of one function into the service of another. In the caphalopod arms, parts of a highly modified molluscan foot (an originally locomotor organ), have come to be largely employed in the capture of food, and in the Decapoda we may have in the peculiar hectocotylized arm of the male a further transformation of function in the interest of reproduction.

These transformations - and they are exceedingly common events in evolutionary history - show us that in attempting to classify the activities of animals on a genetic basis, we cannot proceed as if we were dealing with isolated organisms. It is only through isolation that the usual genetic classification is possible at all. In a genetic classification of organisms the various groups as we trace them back in time fuse into fewer and fewer subdivisions, but in tracing back types of behavior we encounter as it were strands coming in from a variety of sources, combining, segregating and dividing in various ways so that a tree cannot symbolize our system of genetic relationships. Rather we have an intricate network in which there is divergence and convergence all along the course. The situation is somewhat similar to what we encounter in dealing with groups of organisms which freely interbreed. We may have much diversity, a multitude of different types, but no one could work out a strict tree-like classification of such forms. Itis only when groups get sufficiently distinct to emancipate themselves from the network of varied hereditary relationships and go on their own independent ways that we can get them placed in a real genetic grouping. Doubtless much of the difficulty encountered in classifying the races of man is due to this fact. 
Moreover, in a classification of activities we have perforce to deal with a grouping of performances which are carried on by one and the same animal. This in itself creates many problems quite different from those of the systematist whose task is the proper arrangement of organisms as wholes in a genetic system.

The tentative grouping of animal activities that is here sketched is based in part on the ends subserved by different kinds of behavior and in part on certain general similarities which various kinds of behavior exhibit. Only to a minor extent is any use made of possible genetic affinities of different kinds of activities. The procedure is somewhat akin to what one would follow in essaying a classification of organs or diseases or the occupations followed by human beings. In classifying kinds of behavior one is at liberty to proceed on a number of different principles. Professor Warren in his recent paper has classed reflexes into four groups according to the degree to which they may be modified or inhibited by higher processes. When he passes to instincts he employs a quite different basis of grouping.

Making our primary subdivisions on the basis of the relation of behavior to the welfare of species, we may group activities into (1) those which are adaptive, and (2) those which are not, and the former may bedivided into $(1 a)$ those which are concerned with the preservation of the individual, and $(1 b)$ those concerned with the perpetuation of the race. Most kinds of behavior which have been recognized and described have in some way or another something to do with the preservation of the species. Mr. Spencer's definition of life as the continuous adjustment of internal relations to external relations, laying emphasis as it does on adjustment (i.e., adaptation) practically ignores the existence of anything in vital activity which does not make either for individual or race preservation. In his interesting but somewhat disappointing chapter on the dynamic element in life in the second edition of his Principles of Biology, Mr. Spencer gives a belated recognition of the inadequacy of his previous formula in that, among other shortcomings, it does not provide for various forms of dysteleological activity. The primary group of dysteleological kinds of behavior is of course a hodge-podge of 
all sorts of performances resembling each other in nothing except their lack of utility. It is a group recruited from all kinds of behavior, simple and complex, individual and social. Many of the acts in this category are mere aberrant derivatives of purposive acts or acts misdirected or misapplied. Many are the expression of sheer undirected activity. Some acts, like the fits of animals, are pathological. Others may be the expression of old forms of behavior which persist like rudimentary organs under circumstances with which they are not in harmony. Some, like tropistic responses to the electric current and to a less extent other tropisms, may be an incidental result of the creature's organization occurring with no reference to its welfare. A large and instructive treatise might be written on such forms of behavior. Obviously it would be much more voluminous if it included the behavior of man.

The division of purposive behavior into self-maintaining and race-maintaining needs no comment. It is as old as Aristotle and represents a perfectly obvious cleavage, although it is equally obvious that many subordinate activities subserve both ends. Self-maintaining activities are grouped into three divisions, (1) the sustentative which concern themselves with food, water, oxygen, etc., (2) the protective, and (3) the ameliorative. Most animal activities concerned with self preservation are either directed toward securing nutriment or protecting the body from inimical agencies. Nevertheless there is a group of acts which, while promoting life, can scarcely be called protective without extending considerable and perhaps unduly the ordinary meaning of that term. Such performances as sleeping or basking in the sun, if we call these acts, or at any rate such performances as mere exercise and many forms of play are only protective in a very indirect sense, although they may conduce to the preservation of the body. I have accordingly grouped such indirectly preservative acts under a distinct category designated ameliorative. A pig wallowing comfortably in the mud affords a good illustration of behavior coming under this rubric.

Recurring to the sustentative activities, it may be pointed out that these fall into a number of different classes. Oldest, 
TABLE 1

General grouping of animal activities

Useless tropistic reactions

Misdirected instinct

$\left\{\begin{array}{c}\text { Non- } \\ \text { adaptive }\end{array} \quad\left\{\begin{array}{l}\text { Abnormal sex behavior } \\ \text { Pathological activity: fits } \\ \text { Useless social activity } \\ \text { Superfluous random movements }\end{array}\right.\right.$

$\left\{\begin{array}{c}\text { Non- } \\ \text { adaptive }\end{array} \quad \begin{array}{l}\text { Abnormal sex behavior } \\ \text { Pathological activity: fits } \\ \text { Useless social activity } \\ \text { Superfluous random movements }\end{array}\right.$

$\left\{\begin{array}{c}\text { Non- } \\ \text { adaptive }\end{array} \quad \begin{array}{l}\text { Abnormal sex behavior } \\ \text { Pathological activity: fits } \\ \text { Useless social activity } \\ \text { Superfluous random movements }\end{array}\right.$

Superfluous random movements

Devouring food

Discrimination of food

Capture of food

Activities preparatory

to capture as mak-

ing snares, pitfalls,

hunting, stalking

Collection of food, digging, boring, gnawing

Migration

Caring for food for future use, hiding, burying, storing

Preparation of food

Self-main-
taining

Against enemies (see table 2)

Against inanimate forces, reactions to heat, light, gravity,

Protective chemicals, etc.

Against inanimate objects, i.e., avoidance of moving objects, cleaning movements, etc.

Adaptive

Race-maintaining Ameliorative $\left\{\begin{array}{c}\text { Rest, sleep, exercise, } \\ \text { play, basking. }\end{array}\right.$

(Of male toward female: Copulation

Sexual be- $\{$ Sex discrimination, havior seeking the female Courtship, sex calls

Battling for female

Of female toward male, Resisting, accepting alluring, coyness

$\begin{gathered}\text { Parental be- } \\ \text { havior (see } \\ \text { table 3) }\end{gathered}$
$\begin{gathered}\text { Parents toward off- } \\ \text { spring } \\ \text { Offspring } \\ \text { ents }\end{gathered}$
$\begin{gathered}\text { Social be- } \\ \text { havior (see } \\ \text { table 4) }\end{gathered}$


phylogenetically, are the movements directly concerned with taking in or swallowing food. As animals become more highly developed, we meet with an elaboration of preparatory or subsidiary actions. Thus associated with taking in food are acts which bring the organism in contact with food, and acts which involve a discrimination between what serves as food and what does not. In many animals taking in food is preceded by capturing or overcoming some other organisms, or by other activities such as digging, boring or gnawing. In higher forms, especially, activities accessory to these are added such as hunting, making snares or lying in wait. In exceptional cases there may be storing of food, as in rodents, many bees, and some specres of ants. Even more elaborate behavior is occasionally developed, as shown in leaf-cutting ants, which devour fungi grown upon the prepared leaves which are carried to the nest. The elaboration of activities of varying degrees of indirectness which are subsidiary to food taking would afford an interesting phylogenic enquiry to which we can do no more here than simply call attention.

Protective activities may be grouped into those concerned with general forces such as heat, light, gravity, etc., and those concerned with definite objects. Under the former come most of the forms of behavior commonly called tropisms, in so far as these are directly or indirectly subservient to life. For most purposes of analysis, however, it is doubtless most advantageous to consider tropisms as general modes of response quite regardless of their utility.

Reactions of a protective nature directed to specific objects are common and fall quite naturally into two groups: (1) those in relation to living objects, usually enemies, and (2) those in relation to objects which are not living. Protection from enemies may be secured (a) through escaping from them by some means, or (b) by standing ground and making some defense. Defense may be accomplished by $(b 1)$ offering passive resistance such as closing a shell, erecting spines, or otherwise rendering the animal difficult to attack. Or $(b 2)$ an animal may defend itself by actively inflicting some injury on its assailant. Primarily such 
active defense consists in retaliatory infliction of injury after attack. But in some cases, especially in higher forms, we meet with an aggressive pugnacity which does not wait for an attack to be made, but incites to attacks which are apparently unprovoked. The function of such gratuitous hostility is, however, primarily protective. It is often advantageous to take the offensive against a potential enemy. Animals which are particularly irascible are often given a wide berth and this often means the undisputed possession of many desirable things. To a cer-

TABLE 2

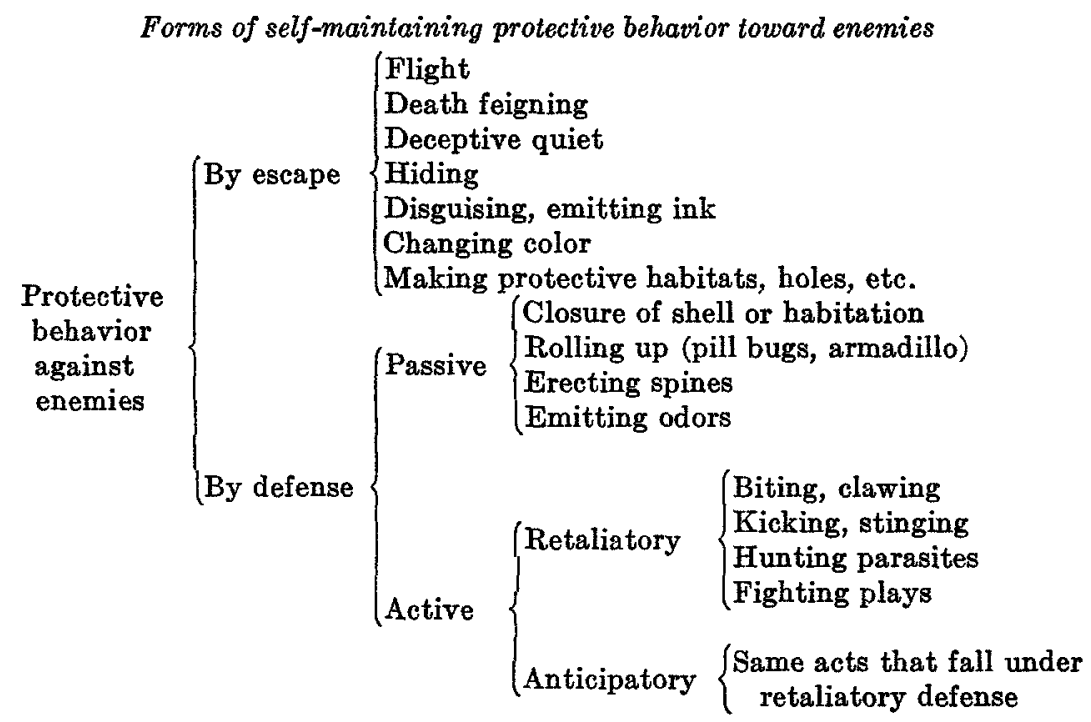

tain extent, also, aggressive pugnacity may be the expression of the fighting instinct which, if it does not find sufficient exercise through provocation, may tend to discharge itself without the usual stimulus.

Along with active defense should be placed playful or makebelieve fighting which is so common among higher animals and which may be regarded, in accord with the theory of Groos, as preparatory to serious encounters.

Activities directly or indirectly subservient to race maintenance form a large and varied group. Obviously, they include 
(first), sex behavior, and (second) parental care, and I have also placed (third) social behavior under this head because such behavior, while often subserving the interest of the individual, is primarily of service to the group and much of it is probably derived phylogenetically from activities concerned with the maintenance of the family. Sex behavior is devoted to the end of securing the meeting of ova and spermatozoa. It emerges gradually from the simple physiological functions of forming and discharging the sex cells. There is no sex behavior properly so-called in sponges, coelenterates, echinoderms, many mollusks (such as lamellibranchs) and various other invertebrates which simply discharge their sex cells into the water and leave their meeting to chance. In some of the Protozoa we may have sex behavior involved in conjugation, the relation of which to the behavior of gametes in multicellular organisms we shall not here discuss. Some of the invertebrates discharge their sex cells under the stimulus afforded by the proximity of the other sex and in animals in which internal fertilization does not occur we often find strong instincts leading to a close association of the sexes and a simultaneous discharge of the sex cells during the breeding season as in many fishes. In some animals that discharge their sex into the water, proximity is insured by the development of instincts of the male to seize and retain the female as in frogs and toads. Association of the sexes, whether it involves internal fertilization and the consequent development of copulation, or whether it involves the delicate responsiveness insuring the simultaneous discharge of sex productsinto the water, entails the development of the power of sex recognition and activities on the part of the males for seeking and seizing the females. Such a procedure involves a whole stream of accessory activities which have been of the greatest importance in the evolution of behavior. Courtship, the song of birds, battles on the part of males for the possession of females with the accompanying evolution of larger size, strength, weapons of defense and pugnacity in the male sex, are among the many subsidiary developments which have gradually been added to the primary function of sex. The evolution of sex behavior, al- 
though most conspicuous in the male, has had its complementary counterparts in the female sex in the development of various instincts such as coyness and alluring instincts, as well as other acts more closely associated with the propagation of the species.

The category of parental behavior is used in a broad sense to include not only the behavior of parents toward offspring but the reactions of offspring to parents, and, in the former case, the behavior of parents not only toward young, but in relation to the eggs from which the young are to emerge. Behavior toward eggs includes the activities of egg laying, protecting and incubating eggs, nest building, selecting a site for eggs and often providing food for larvae to which the eggs will give rise. As I have elsewhere attempted to show, ${ }^{1}$ care for young first developed by extending care directed to eggs to what comes out of the eggs. And when this step is taken a line of evolution is entered upon which has led not only to greater and greater extensions and elaborations of parental care, but also to the various forms of social behavior.

As the care for offspring has evolved there has been a coordinate development of behavior of the young towards their parents. Following, cuddling, making cries, obeying signals, such as the danger chirr of the domestic hen, and imitation are among the acts by which the young derive benefit from the association with their parents, and many of these acts come, in time, to have a significance in social life far beyond the limits of the family group.

Social behavior, like self-maintaining behavior, I have divided into the sustentative, the protective and the ameliorative. There are sustentative activities which are social, such as mutual feeding among ants, bees and termites, collecting, preparing and storing food for the group, leading others to food, as in ants, and group attacks upon prey, as in packs of wolves. But most social behavior is primarily protective. And protective social behavior, like protective individual behavior, is directed (1) toward inanimate forces and objects on the one hand, and

1 Studies in Animal Behavior. Ch. 2. The Evolution of Parental Care. 
(2) toward animate creatures, largely in the form of enemies, on the other. Under the first there is the construction of common habitations or other means of shelter against the elements, and keeping the habitation clean (as in ants and bees). The chief

TABLE 3

Forms of parental behavior

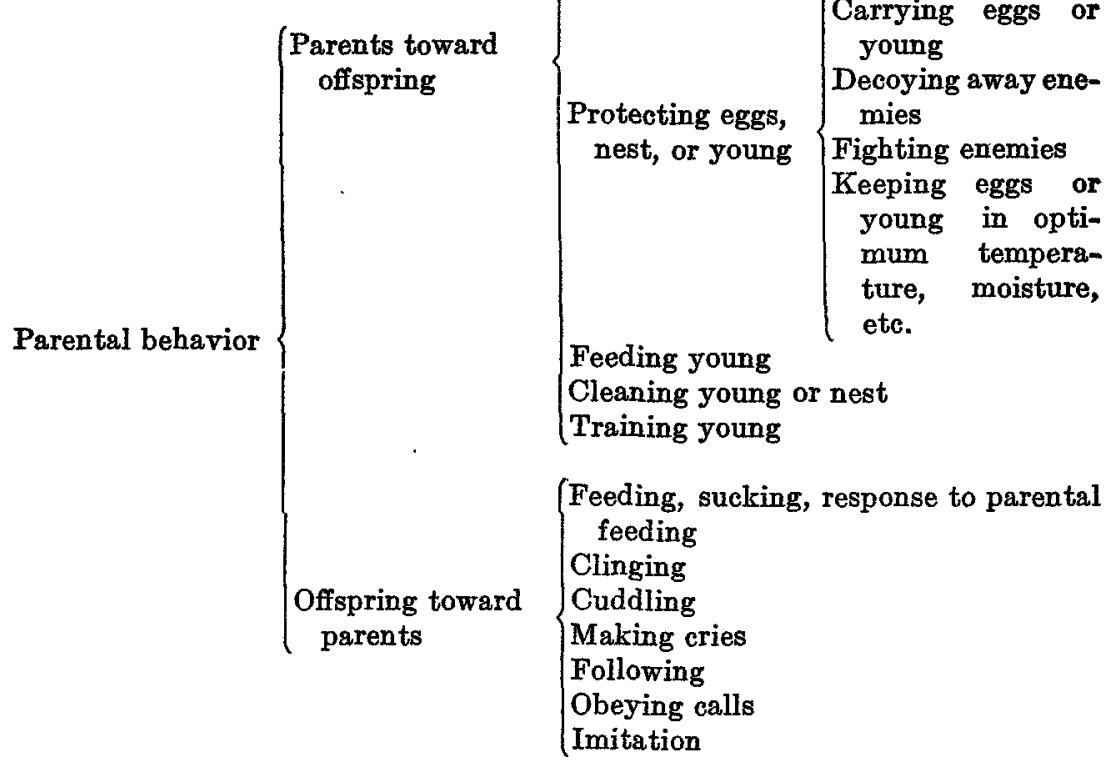

Egg laying $\left\{\begin{array}{c}\text { Oviposition } \\ \text { Selecting suitable places } \\ \text { or hosts (as in para- } \\ \text { sites) } \\ \text { Preparation of places for } \\ \text { eggs }\end{array}\right.$
Nest building, hole digging
Incubation
Provisioning eggs

protective efforts of animals, however, are concerned with other living creatures. The most primitive exhibition of such behavior is direct cooperative defense against an attacking enemy. Shelter making is often more for defence against enemies than for 
protection from the elements. Coöperative offensive undertakings naturally grow out of defensive efforts as in individual behavior and may likewise be regarded as primarily anticipatory defense. Actions subsidiary to defense naturally assume importance as life becomes more complex. We see the develop-

TABLE 4

Classification of the forms of social behavior

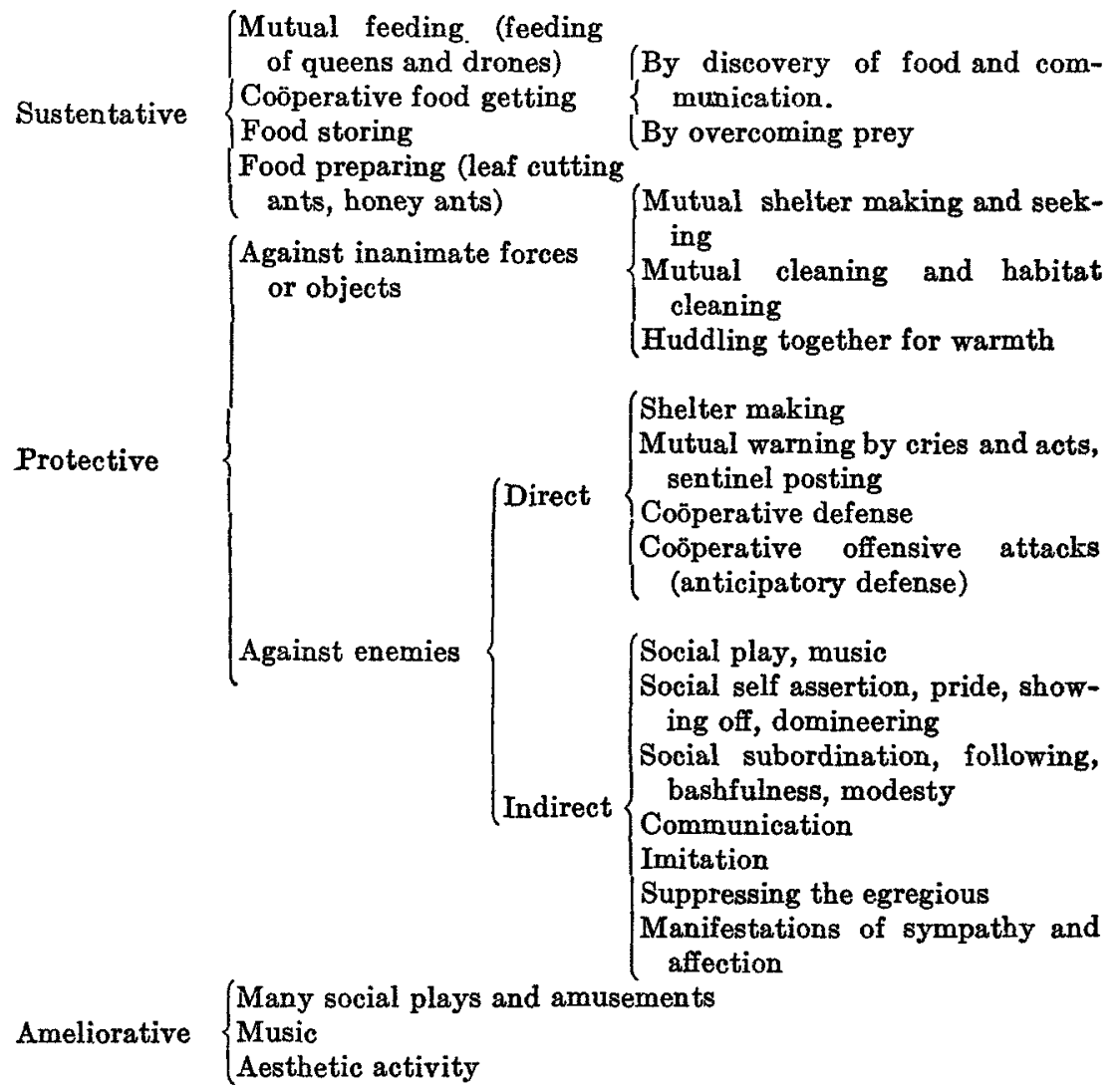

ment of warning behavior, danger cries, the posting of sentinels, and the communication of a hostile attitude by the spread of the angry hum in a hive of bees.

Besides the defensive actions of social animals and the actions immediately subservient to the function of protection, 
there is a large class of social activities whose connection with defense is quite indirect but whose raison d'être is nevertheless to be found, at least in part, in their subservience to this end. The instincts which make for social subordination such as bashfulness, the tendency to attack or suppress the egregious, sequacity, and to a certain extent imitation, make indirectly for the solidarity of the group upon which successful defense often depends. Mutual aid and the sympathy by which in higher forms such aid is prompted, as well as many of the play activities of social animals contribute also to the same end. On the other hand, we have the instinctive exhibition of pride, self assertion, the tendency to dominate and assume leadership entering, along with apparently opposite or contradictory traits, into the composition of the higher animals and man. I shall not discuss the interesting problem of how far the original nature of man can be interpreted from the standpoint of adaptive responses. There is in all animals, and possibly to a relatively large extent in human beings, an ingredient of biologically nonsignificant behavior. How large is this ingredient of undisciplined activity which has never been worked in for military service is difficult to determine. The Darwinian must agree with the dictum of Schiller, "Ernst ist das Leben,"-life is serious business. But while life is ever devoted to its own maintenance, to a considerable and not accurately determined extent it indulges in just frills. The Darwinians may argue, often with reason, that what appear to be just frills have nevertheless their indirect utility. The Groos theory of play would reduce the most wanton gambols of young lambs to preparation for the serious business of later life. Even our social plays and sports may prepare for social life and tend to promote social solidarity. But even accepting such an interpretation of play as valid, it can at least represent but a general truth. Just as naturalists are coming to regard many of the specific characteristics of organisms of no utility, so there are many acts which have no biological value or are even injurious. And when we come to interpret the behavior of human beings in relation to a physical and social environment that is ever changing, it is obvious, I believe, that such behavior should become much more common. 
To a larger extent than obtains in lower forms, perhaps, social behavior in higher animals, and especially in man, may be described as ameliorative, although it is always difficult to draw a distinction between this category and acts which are indirectly protective. Much of human social behavior, when it has any biological significance at all, is not directed toward preparing, even in sport, for any particular defensive action. Our various forms of amusement, so far as they can be said to enhance life, have a general rather than a specific benefit. The same is probably true, although to $\dot{a}$ less extent, of the social plays of animals.

The foregoing classification of animal activities is confessedly imperfect in many ways. It presents only one system of grouping out of many which might be devised and which may have their special advantages. The attempt to class forms of behavior naturally suggests many problems of derivation of forms of activity. It is perhaps useful in aiding us to gain a comprehensive view of animal activities; it may help us to conceive how they have unfolded, how accessory activities have been added to primitive ones, and to understand how forms of behavior have become interrelated in various ways in the course of evolution. 